\title{
Unassisted establishment of biological soil crusts on dryland road slopes
}

\author{
Laura Concostrina-Zubiri, Juan M. Arenas, Isabel Martínez, and Adrián Escudero \\ Área de Biodiversidad y Conservación, Departamento de Biología, Geología, Física y Química Inorgánica, \\ Universidad Rey Juan Carlos, Móstoles, 28933 Madrid, Spain \\ Correspondence: Laura Concostrina-Zubiri (laura.concostrina@urjc.es) and Juan M. Arenas \\ (juanmariaae@gmail.com)
}

Received: 13 January 2019 - Revised: 12 May 2019 - Accepted: 15 May 2019 - Published: 6 June 2019

\begin{abstract}
Understanding patterns of habitat natural recovery after human-made disturbances is critical for the conservation of ecosystems under high environmental stress, such as drylands. In particular, the unassisted establishment of nonvascular plants such as biological soil crusts or biocrust communities (e.g., soil lichens, mosses and cyanobacteria) in newly formed habitats is not yet fully understood. However, the potential of biocrusts to improve soil structure and function at the early stages of succession and promote ecosystem recovery is enormous. In this study, we evaluated the capacity of lichen biocrusts to spontaneously establish and develop on road slopes in a Mediterranean shrubland. We also compared taxonomic and functional diversity of biocrusts between road slopes and natural habitats in the surroundings. Biocrust richness and cover, species composition, and functional structure were measured in 17 road slopes (nine roadcuts and eight embankments) along a $13 \mathrm{~km}$ highway stretch. Topography, soil properties and vascular plant communities of road slopes were also characterized. We used Kruskal-Wallis tests and applied redundancy analysis (RDA) to test the effect of environmental scenario (road slopes vs. natural habitat) and other local factors on biocrust features. We found that biocrusts were common in road slopes after $\sim 20$ years of construction with no human assistance needed. However, species richness and cover were still lower than in natural remnants. Also, functional structure was quite similar between roadcuts (i.e., after soil excavation) and natural remnants, and topography and soil properties influenced species composition while environmental scenario type and vascular plant cover did not. These findings further support the idea of biocrusts as promising restoration tools in drylands and confirm the critical role of edaphic factors in biocrust establishment and development in land-use change scenarios.
\end{abstract}

\section{Introduction}

Biological soil crusts (biocrusts) have earned a place as key ecosystem components in drylands in the last decades (Weber et al., 2016a). They are complex communities composed of lichens, bryophytes, fungi, cyanobacteria and other microorganisms living on and interacting with the first soil layers, and are found in almost every dryland occurring in stressful conditions, i.e., water scarcity and high solar radiation and temperatures. Biocrusts contribute greatly to ecosystem diversity, with several tens of species per square metre, and to ecosystem functioning, being critical in the fixation of carbon and nitrogen (Elbert et al., 2012), controlling topsoil structure (Jimenez Aguilar et al., 2009), chemistry
(Delgado-Baquerizo et al., 2015) and hydrology (Chamizo et al., 2013), and also modulating biotic interactions (Luzuriaga et al., 2012). Moreover, due to the functional roles they perform and their ability to establish and develop in very harsh environments, biocrusts have been pointed out as promising tools in dryland restoration (Bowker, 2007). Some of the biocrust constituents are early, fast colonizers of degraded areas with enormous potential to aid and speed up ecosystem structure and functioning recovery, e.g., stabilizing soil surface, improving soil fertility, maintaining soil humidity and promoting the establishment of vascular plants (Weber et al., 2016a). This is particularly true in strongly disturbed areas under high abiotic stress, where vascular plant development 
is less likely to occur due to a higher demand on soil resources and lower tolerance of water scarcity, among others (Bowker, 2007).

Biocrusts have been shown to recover naturally without assistance from mechanical disturbances, such as grazing, trampling and vehicle driving, and also from fire, at varying recovery rates and following different community trajectories depending on the disturbance type, intensity and timing (Belnap and Eldridge, 2003). However, little is known about natural recovery of biocrusts in newly formed and emergent habitats such as those generated after the construction of linear infrastructures which include massive soil removal or the accumulation of exogenous soil material. At the very fine spatial scale (i.e., topsoil, area $<10 \mathrm{~m}^{2}$ ), several studies have evaluated biocrust natural colonization and establishment after biocrust removal (i.e., scalping). Recovery rates range from less than 3 years for cyanobacteria, commonly the earliest, fastest colonizers within biocrusts, up to a few decades or almost a millennium for bryophytes and lichens, the typical components of more developed, mature biocrusts (reviewed in Weber et al., 2016b). Similarly to biocrust recovery in secondary succession, the colonization and establishment of biocrusts largely depend on climate, particularly, precipitation amount and timing after disturbance, and soil properties, such as soil stability and nutrient concentration (Weber et al., 2016b).

Surprisingly, to our knowledge, there is only one study focusing entirely on the recovery of biocrust communities on road slopes (Chiquoine et al., 2016). Yet, Chiquoine et al. (2016) did not focus on natural colonization but on successful establishment after applying biocrust inoculum, among other restoration treatments. This is a bit striking since there is no baseline for comparison. Therefore, no previous study has evaluated the unassisted recovery of biocrusts on road slopes, and this limited knowledge on biocrust recovery under natural conditions weakens many projects of ecological restoration of road slopes in drylands.

In contrast, many studies have highlighted the role of natural colonization in the establishment of vascular vegetation on road slopes (Bochet et al., 2007; Mola et al., 2011; Arenas et al., 2017a, b). In Mediterranean drylands, native vascular plants can establish and develop well in road slopes in the absence of human assistance when the slope is gentle $\left(<45^{\circ}\right)$ (Bochet and García-Fayos, 2004) and sufficient propagule is available from the surroundings (Arenas et al., 2017b). However, species composition differs notably from communities found in the natural surrounding areas, mainly due to topography and modification of initial soil conditions derived from the process of road slope construction (Bochet and García-Fayos, 2004; Arenas et al., 2017a). Moreover, within road slopes, roadcuts and embankments have very different structural properties (e.g., soil removal vs. soil application, respectively) and environmental characteristics, and as a result, further differences can be found between their respective plant communities at the compo- sitional level (Arenas et al., 2017a). For biocrusts, we expect to find processes of colonization and community assembly on road slopes similar to those that occur for vascular vegetation, and therefore evidence the ecological interest of natural colonization as a useful biocrust restoration measure. In particular, we hypothesized that biocrusts establish easily in the road slopes, provided that biocrusts are common and abundant in the surroundings (i.e., inoculum availability) and because of their capacity to tolerate harsh environmental conditions typical for newly created habitats (e.g., very thin soil, high radiation inputs) (Weber et al. ,2016b). Nevertheless, we expect to find marked differences in biocrust composition depending on road slope type (i.e., roadcut vs. embankment), topography, soil properties and vascular plant abundance since the diversity of these organisms is highly sensitive to changes in (i) climate at the local and microscale given by topography, e.g., sun vs. shade environments (Pintado et al., 2005); (ii) soil physicochemical properties, e.g., texture (Fischer and Subbotina, 2014), nutrient content (Bowker et al., 2006) and pH (Ochoa-Hueso et al., 2011); and (iii) biotic interactions, especially with vascular plants, e.g., biocrust-plant facilitation-competition processes (reviewed in Bowker et al., 2016). In this study, we aimed to assess the potential of lichen biocrusts to colonize and prosper in pioneer habitats under natural conditions (i.e., with no artificial assistance). We focused only on lichens because they are the most conspicuous, rich and common components of biocrusts in Mediterranean grasslands and shrublands (Concostrina-Zubiri et al., 2014), even in fragmented landscapes (Concostrina-Zubiri et al., 2018).

Specifically, we addressed the following questions: (1) can lichen biocrusts establish on road slopes spontaneously? If so, (2) what species and functional attributes characterize the newly formed communities? Regarding the functional attributes characterizing these communities, we focused on eutrophication tolerance, gypsum tolerance, because our biocrust model occurs in this type of soil (Concostrina-Zubiri et al., 2018), and thallus continuity to test the following hypotheses: (i) lichen biocrust communities in the road slopes are more tolerant to high nutrient levels (e.g., derived from the road traffic and the subsequent passive air fertilization), (ii) they present a higher tolerance of/affinity to gypsum content, as expected in a less developed topsoil layer at road slopes compared to natural remnants where soil carbon and other nutrients had higher levels (Arenas et al., 2017a); and (iii) lichen biocrusts with a less continuous thallus are more likely to colonize and prosper in road slopes, characterized by a more hostile microenvironment. (3) What is the role of habitat scenario type (e.g., road slopes vs. natural areas) and other local factors (i.e., topography, soil properties and vascular plant communities) in determining the structure and composition of lichen biocrusts? By addressing these questions, we could identify the factors that determine the natural colonization of biocrust in road slopes, and point out some restoration measures to carry out in road slopes for promot- 


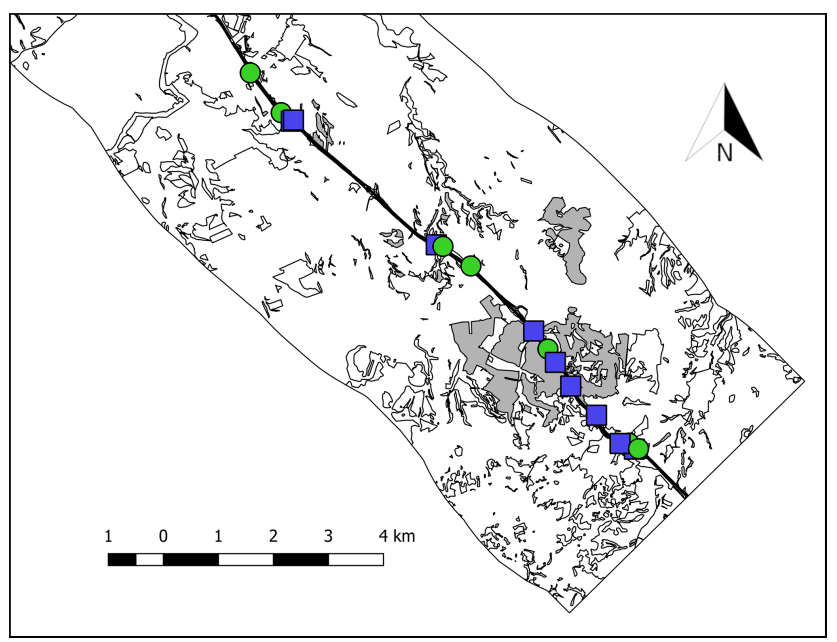

Figure 1. Map of the study area showing the road (in black), roadcuts (squares), embankments (circles) and natural remnants (in grey).

ing the natural recovery of biocrusts. Beyond road restoration, this information is critical to the progress of current research on artificial recovery of biocrusts, a growing body of work in the last years.

\section{Material and methods}

\subsection{Study area}

This study was conducted in the road slopes and surrounding natural habitat remnants of a typical Mediterranean gypsum shrubland in central Spain. The study area comprised two adjacent rectangles, each $3 \mathrm{~km}$ wide, along both sides of a $13 \mathrm{~km}$ segment of the A3 national highway (Fig. 1) between Fuentidueña del Tajo $\left(40^{\circ} 7^{\prime} 7.96^{\prime \prime} \mathrm{N}, 3^{\circ} 9^{\prime} 41.96^{\prime \prime} \mathrm{W}\right.$, $570 \mathrm{~m}$ a.s.l.) and Belinchón $\left(40^{\circ} 2^{\prime} 52.95^{\prime \prime} \mathrm{N}, 3^{\circ} 3^{\prime} 29.68^{\prime \prime} \mathrm{W}\right.$, $761 \mathrm{~m}$ a.s.l.). The highway goes through an extensive landscape of cereal croplands where small patches of natural vegetation remain. The vegetation in these natural patches is characterized by an open shrubland dominated by gypsophytes such as Thymus lacaitae Pau, Lepidium subulatum L. and Helianthemum squamatum (L.) Dum. Cours. accompanied by perennial grasses such as Stipa tenacissima L. and Koeleria castellana Boiss. \& Reut., among others. Soils are predominantly Typic Gypsiorthid ( $>70 \%$ gypsum soil content). The climate in the area is Mediterranean semiarid with a mean annual precipitation of $443 \mathrm{~mm}$ and mean annual temperature of $14^{\circ} \mathrm{C}$, with a very intense summer drought (Ninyerola et al., 2005).

\subsection{Biocrust sampling and identification}

We selected 17 road slopes along the $13 \mathrm{~km}$ highway stretch and differentiated two types because of big differences in their structural and physicochemical properties; (i) roadcuts $(n=9)$, which are constructed by excavation, resulting in areas of bare soil and exposed bedrock; and (ii) embankments $(n=8)$, which are constructed by heaping and compacting materials and eventually receiving topsoil treatments (Tormo et al., 2009). At each road slope, we established a central sampling plot $(2.40 \mathrm{~m} \times 2.40 \mathrm{~m})$ and regularly divided it in 64 quadrats $(30 \mathrm{~cm} \times 30 \mathrm{~cm}$ cells $)$. Then, we randomly selected 10 quadrats to estimate lichen biocrust species abundance visually as the percentage cover per species. We also sampled lichen biocrust communities in natural habitat remnants adjacent to the highway to compare lichen biocrust communities colonizing the emergent habitats (road slopes) to natural, well-established lichen biocrusts. To do so, we selected 50 natural shrubland remnants immersed in an agricultural matrix in a ca. $76 \mathrm{~km}^{2}$ area comprising two adjacent $3 \mathrm{~km}$ rectangles at both sides of the $13 \mathrm{~km}$ stretch of the national motorway (Fig. 1). Then, we followed the same sampling design for each remnant as in the road slopes (see Concostrina-Zubiri et al., 2018, for more details of the study system). We focused only on lichen biocrusts because they are the most conspicuous, rich and common components of Mediterranean biocrusts (Concostrina-Zubiri et al., 2014, 2018) and allowed a relatively easy identification in the field. Other typical biocrust organisms such as cyanobacteria and mosses were not considered in this study, although they were present in the road slopes but marginally or not visually apparent (personal observation). Lichen biocrusts were identified to the species level when possible, following Nimis and Martellos (2016) and Prieto et al. (2010a, b) for Placidium. We collected lichen specimens of species that could not be identified to the species level in the field for identification in the laboratory. We identified a total of 18 taxa: 15 lichens and three lichen groups identified in the field as Enchylium complex (dominated by E. tenax (Sw.) Gray, E. coccophorum (Tuck.) Otálora, P. M. Jørg. \& Wedin and Blennothallia crispa (Hudson) Otálora, P. M. Jørg. \& Wedin), Gyalolechia complex (including G. fulgens (Sw.) Søchting, Frödén \& Arup and G. subbracteata (Nyl.) Søchting, Frödén \& Arup) and Placidium complex (dominated by P. squamulosum (Ach.) Breuss, P. pilosellum (Breuss) Breuss and Clavascidium lacinulatum (Ach.) M. Prieto). Lichen biocrusts are referred to hereafter as "biocrusts" and species and species complexes are referred to as "species" for simplicity. Nomenclature follows Hladun and Llimona (2002-2007) and Prieto et al. (2010a, b), except Clavascidium lacinulatum (Ach.) M. Prieto, which follows Prieto et al. (2012), Enchylium spp., which follow Otálora et al. (2014) and Gyalolechia spp., which follow Arup et al. (2013).

\subsection{Characterization of biocrust communities}

We characterized biocrust communities by measuring total cover (i.e., mean percentage cover), species richness (i.e., mean number of biocrust species s.l.), species composition 
and functional structure at each plot. To assess functional structure, we first classified each species considering different ecological features, i.e., eutrophication tolerance, gypsum tolerance and thallus continuity (Table 2). The eutrophication tolerance of biocrusts was classified into two categories, following Nimis and Martellos (2017): (1) species not resistant to eutrophication or resistant to very weak eutrophication (low); (2) species resistant to weak eutrophication (medium). The gypsum tolerance of each species was classified into three categories following Concostrina-Zubiri et al. (2014) and field observations: (1) species that are rarely found on gypsum soils (low), (2) species that are less abundant on gypsum soils compared to other substrates (medium), (3) species generally growing on gypsum soils only (high). The thallus continuity was classified into three classes following Nimis and Martellos (2017) and field observations: (1) thallus consisting of disperse squamules or with a fruticose morphology (discontinuous), (2) thallus with more or less contiguous squamules/lobes or with a foliose morphology (semicontinuous) and 3) thallus with a crustoseplacodioid-leprose morphology (continuous). Complexes including several species (i.e., Enchylium, Gyalolechia and Placidium complexes s.l.) were classified as the common category for the species constituting the complexes (i.e., all or most of the species in the complex shared the same functional category; as for Enchylium and Gyalolechia complexes) or as the category for the most abundant species in gypsum soils (following Concostrina-Zubiri et al., 2014, and field observations, as for Placidium complex). Secondly, we evaluated the functional structure of biocrust communities at each plot calculating the eutrophication tolerance index, the gypsum tolerance index and the thallus continuity index by means of the community-weighted mean (CWM) for each ecological feature. CWMs were adapted for each multinomial functional variable. For instance, we calculated eutrophication tolerance (ET) of each plot by using the following index (1):

$\mathrm{ET}=\sum_{\mathrm{sp}=1}^{n} \mathrm{ET}_{\mathrm{sp}} *$ Cover $_{\mathrm{sp}} / \sum_{\mathrm{sp}=1}^{n} \operatorname{Cover}_{\mathrm{sp}}$,

where $\mathrm{ET}_{\mathrm{sp}}$ is the eutrophication tolerance of each species (low, medium), Cover ${ }_{\text {sp }}$ is the estimated cover of each species and $n$ is the species richness in each plot. ET can range between 1 (all species of a plot show low tolerance) and 2 (all species show medium tolerance). The CWM for gypsum tolerance (GT) or thallus continuity (TC) was estimated in the same way as ET, replacing $\mathrm{ET}_{\mathrm{sp}}$ by $\mathrm{GT}_{\mathrm{sp}}$ or $\mathrm{TC}_{\mathrm{sp}}$, with both presenting three levels: low (value $=1)$, medium $($ value $=2$ ) and high (value $=3$ ) for $\mathrm{GT}_{\mathrm{sp}}$ and discontinuous (value $=1$ ), semicontinuous (value $=2$ ) and continuous $($ value $=3$ ) for $\mathrm{TC}_{\mathrm{sp}}$. Therefore, GT and TC can range between 1 and 3.

\subsection{Characterization of road slope topography, soil properties and vascular plant communities}

In order to partial out the effect of topography, soil variability and vascular plants in each plot (on both road slopes and natural remnants), we first measured the slope, aspect and latitude in the center of the plot for calculating the heat load index (McCune and Keon, 2002). The heat load index can be regarded as a measure of potential solar radiation symmetrical about the north-south axis and is expected to influence biocrust establishment and development via soil temperature and moisture modification, among others (Bowker et al., 2016). Then, soil properties were characterized by collecting one soil sample $(5 \mathrm{~cm}$ diameter and $10 \mathrm{~cm}$ deep) under dominant perennial plants ("plant microsite") in each plot. Also, another sample was collected from areas devoid of plant cover ("interspace microsite"), which are typically covered with biocrusts. These samples were collected in $\mathrm{Au}-$ gust when the soil was dry. Samples were analyzed for total organic $\mathrm{C}(\mathrm{OC})$, total $\mathrm{N}$, total $\mathrm{P}, \mathrm{K}, \mathrm{pH}$, electrical conductivity (EC), and two soil enzyme activities related to $\mathrm{C}$ dynamics ( $\beta$-glucosidase) and $\mathrm{P}$ (acid phosphatase) cycles. Laboratory techniques used to determine each soil parameter are explained in Appendix S1. Soil stoniness was also estimated as the percentage cover of rock or rock fragments $>10 \mathrm{~cm}$ in each plot. Finally, the percentage cover of perennial plants (plant cover, hereafter) in each plot was sampled in a parallel study (Arenas et al., 2017a) by visual estimation. Taking into account the plant cover and the bare ground surface of each plot, we calculated a weighted averaged mean value per soil variable considering the samples collected at the plant and interspace microsites. Average values ( \pm SE) for topography variables, soil properties and plant cover at each environmental scenario are shown in Table 3.

\subsection{Data analyses}

To test for differences in total biocrust cover, species richness and CWM for the three functional indices (i.e., eutrophication tolerance, gypsum tolerance and thallus continuity) between environmental scenarios (i.e., embankments, roadcuts and remnants or roadcuts vs. remnants), we conducted nonparametric Kruskal-Wallis tests and, when significant differences were found, we used the Conover-Iman test for post hoc analyses. For total biocrust cover and species richness, we included all plots (i.e., eight embankments, nine roadcuts and 50 natural remnants). However, to calculate the CWM for the three functional indices, we only included plots where lichen biocrust communities and more than one species were present (McCune and Grace, 2002). Therefore, we limited the analysis to six roadcuts and the 50 natural remnants, while embankments were excluded (i.e., only one species was found in this scenario type). Analyses were performed using the "kruskal()" function in the agricolae R package (de 
Table 1. Biocrust species codes and frequency as number and percentage of plots at each scenario. For roadcuts and embankments, two percentages are presented: the first is relative to the total number of plots for each scenario, and the second is relative only to the number of plots where biocrusts were present, in brackets.

\begin{tabular}{ll|rr|rr|r|rr}
\hline \multirow{2}{*}{ Species } & Code & \multicolumn{2}{|c|}{ Embankments } & \multicolumn{2}{c}{ Roadcuts } & Natural remnants \\
\cline { 2 - 7 } & & No & $\%$ & No & $\%$ & No & $\%$ \\
\hline Acarospora nodulosa var. reagens & AcNo & 0 & 0 & 0 & 0 & 12 & 0.24 \\
Acarospora placodiiformis & AcPla & 0 & 0 & 0 & 0 & 7 & 0.14 \\
Buellia zoharyi & BuZo & 0 & 0 & 0 & 0 & 2 & 0.04 \\
Cetraria aculeata & CeAc & 0 & 0 & 0 & 0 & 4 & 0.08 \\
Cladonia convoluta & ClaCo & 0 & 0 & 2 & $0.22(0.33)$ & 30 & 0.60 \\
Diplotomma alboatrum & DiAl & 0 & 0 & 0 & 0 & 14 & 0.28 \\
Diploschistes diacapsis & DiDi & 0 & 0 & 1 & $0.11(0.16)$ & 34 & 0.72 \\
Enchylium complex & EnCo & 5 & $0.62(1)$ & 6 & $0.67(1)$ & 49 & 0.98 \\
Gyalolechia complex & GyCo & 0 & 0 & 6 & $0.67(1)$ & 48 & 0.96 \\
Leproloma sp. & LeSp & 0 & 0 & 1 & $0.11(0.16)$ & 12 & 0.24 \\
Placidium complex & PlaCo & 0 & 0 & 4 & $0.44(0.67)$ & 47 & 0.94 \\
Placynthium nigrum & PlaNi & 0 & 0 & 2 & $0.22(0.33)$ & 18 & 0.36 \\
Psora decipiens & PsoDe & 0 & 0 & 0 & 0 & 44 & 0.88 \\
Psora globifera & PsoGl & 0 & 0 & 0 & 0 & 5 & 0.10 \\
Psora savizcii & PsoSa & 0 & 0 & 0 & 0 & 19 & 0.38 \\
Squamarina cartilaginea & SqCa & 0 & 0 & 0 & 0 & 7 & 0.14 \\
Squamarina lentigera & SqLe & 0 & 0 & 0 & 0 & 38 & 0.76 \\
Toninia sedifolia & ToSe & 0 & 0 & 2 & $0.22(0.33)$ & 45 & 0.90 \\
\hline
\end{tabular}

Table 2. Biocrust species and functional trait categories. See Table 1 for species codes.

\begin{tabular}{llll}
\hline Code & $\begin{array}{l}\text { Eutrophication } \\
\text { tolerance }\end{array}$ & $\begin{array}{l}\text { Gypsum } \\
\text { tolerance }\end{array}$ & $\begin{array}{l}\text { Thallus } \\
\text { continuity }\end{array}$ \\
\hline AcNo & Low & High & Continuous \\
AcPla & Low & High & Continuous \\
BuZo & Low & High & Semicontinuous \\
CeAc & Low & Low & Discontinuous \\
ClaCo & Low & Medium & Semicontinuous \\
DiDi & Medium & Medium & Continuous \\
DiEp & Medium & High & Continuous \\
EnCo & Medium & Medium & Semicontinuous \\
GyCo & Medium & Medium & Semicontinuous \\
LeSp & Low & High & Continuous \\
PlaCo & Medium & Medium & Semicontinuous \\
PlaNi & Medium & Low & Continuous \\
PsoDe & Medium & Medium & Semicontinuous \\
PsoGl & Low & High & Semicontinuous \\
PsoSa & Low & Medium & Semicontinuous \\
SqCa & Medium & Medium & Continuous \\
SqLe & Low & Medium & Continuous \\
ToSe & Medium & Medium & Semicontinuous \\
\hline
\end{tabular}

Mendiburu, 2017). The Bonferroni correction was used to adjust $p$ values for multiple comparisons.

The relative importance of the type of environmental scenario on biocrust composition (i.e., species abundance per site matrix) was evaluated using redundancy analysis (RDA).
RDA is a linear ordination method, like principal component analysis, where the response variables (i.e., species composition) are modeled as a function of explanatory or constraining variables (i.e., environmental variables; Zuur et al., 2007). There are as many RDA axes ("constrained axes") as there are continuous explanatory variables or $(n-1)$ levels in nominal explanatory variables. Once all possible RDA axes have been calculated, a series of principal component analysis (PCA) axes are calculated to maximize the explanation of the remaining variation in the data ("unconstrained axes"). In our case, we limited the RDA to roadcuts and natural remnant scenarios where biocrusts and more than one species were present ( 6 and 50 plots, respectively), as for CWM. This means we only used a nominal variable with two levels and, thus, only one RDA axis was calculated, followed by PCA axes. Because Euclidean distance (used in RDA) is inappropriate for raw species abundance data involving many zero values, the species abundance matrix was transformed using the Hellinger standardization (Legendre and Gallagher, 2001). RDA was performed using the "rda()" function in the vegan $\mathrm{R}$ package (Oksanen et al., 2018). Then, to examine if topography, soil properties and plant cover influenced the composition of biocrust communities, the aforementioned groups of variables were fitted to the RDA, separately, and their significance was tested using the "envfit()" function in the vegan R package (Oksanen et al., 2018). Finally, three partial RDAs were conducted to determine the relative importance of the type of environmental scenario after removing the effect of topography, soil and plant cover, 
Table 3. Average values ( \pm SE) for topography, soil properties and plant cover at each scenario. For each variable the significance value of the corresponding Kruskal-Wallis test is given. Different letters indicate significant differences (Conover-Iman test for post hoc comparisons, $p<0.05)$.

\begin{tabular}{|c|c|c|c|c|c|c|c|}
\hline Variable & $p$ & Embankme & & Roadcuts & & \multicolumn{2}{|c|}{ Natural remnants } \\
\hline \multicolumn{8}{|l|}{ Topography } \\
\hline Slope $\left(^{\circ}\right)$ & 0.000 & $30.75 \pm 3.72$ & $a$ & $42.83 \pm 2.41$ & $a$ & $7.52 \pm 0.45$ & $b$ \\
\hline Heat load & 0.460 & $0.85 \pm 0.08$ & $a$ & $0.69 \pm 0.10$ & $a$ & $0.93 \pm 0.01$ & $a$ \\
\hline \multicolumn{8}{|l|}{ Soil property } \\
\hline \multicolumn{8}{|l|}{$\beta$-glucosidase } \\
\hline$\left(\mu \mathrm{mol} \mathrm{PnP} \mathrm{g}{ }^{-1} \mathrm{~h}^{-1}\right)$ & 0.004 & $3.23 \pm 0.55$ & $a$ & $1.56 \pm 0.32$ & $a b$ & $1.35 \pm 0.10$ & $b$ \\
\hline Acid phosphatase & & & $a$ & & & & \\
\hline $\mathrm{N}(\%)$ & 0.000 & $2.06 \pm 0.49$ & $\begin{array}{r}a \\
a b\end{array}$ & $1.26 \pm 0.21$ & $\begin{array}{l}a \\
b\end{array}$ & $\begin{array}{l}0.31 \pm 0.04 \\
2.69 \pm 0.15\end{array}$ & $\begin{array}{l}a \\
a\end{array}$ \\
\hline $\mathrm{P}\left(\mathrm{mg} \mathrm{kg}^{-1}\right)$ & 0.501 & $0.51 \pm 0.09$ & $a$ & $0.38 \pm 0.09$ & $a$ & $0.41 \pm 0.03$ & $a$ \\
\hline $\mathrm{K}(\mathrm{ppm})$ & 0.006 & $0.12 \pm 0.03$ & $a b$ & $0.13 \pm 0.04$ & $a$ & $0.05 \pm 0.00$ & $b$ \\
\hline $\mathrm{OC}(\%)$ & 0.000 & $1.58 \pm 0.36$ & $a b$ & $0.83 \pm 0.15$ & $b$ & $2.08 \pm 0.11$ & $a$ \\
\hline $\mathrm{pH}$ & 0.006 & $8.00 \pm 0.06$ & $a$ & $7.77 \pm 0.06$ & $a b$ & $7.75 \pm 0.03$ & $b$ \\
\hline $\mathrm{EC}\left(\mathrm{dS} \mathrm{m} \mathrm{m}^{-1}\right)$ & 0.002 & $0.72 \pm 0.29$ & $b$ & $1.89 \pm 0.08$ & $a$ & $1.64 \pm 0.08$ & $a$ \\
\hline Stoniness $(\%)$ & 0.000 & $8.25 \pm 3.22$ & $a$ & $26.44 \pm 10.86$ & $a$ & $2.30 \pm 0.91$ & $b$ \\
\hline Plant cover $(\%)$ & 0.540 & $38.75 \pm 7.19$ & $a$ & $29.00 \pm 6.13$ & $a$ & $32.24 \pm 2.02$ & $a$ \\
\hline
\end{tabular}

separately. The partial RDAs were carried out using the "rda" function in the vegan $\mathrm{R}$ package. The significance (Type III ANOVA) of the RDA and the partial RDAs was analyzed using permutation tests with 999 randomizations using the "anova.cca()" function in the vegan R package (Oksanen et al., 2018). All statistical analyses were performed using the $R$ software, version 3.5.1 (http://cran.r-project.org/, last access: 1 December 2018).

\section{Results}

Biocrusts were naturally present in about two-thirds of both the embankments (five out of eight) and roadcuts (six out of nine, Table 1). We found a total of eight biocrust species in road slopes; all of them were present in the roadcuts, but only one (i.e., Enchylium complex) in the embankments (Table 1). The total number of biocrust species in natural areas was 18, including those present in road slopes. We also found one lichen species in natural areas with a very poorly developed thallus that could not be identified, and it was then discarded for further analysis in this study. The most frequent species in the roadcuts were Enchylium complex and Gyalolechia complex, both present in six out of nine plots (Table 1). Additionally, Gyalolechia complex had the highest mean cover in the roadcut scenario $(>1 \%)$. Leproloma sp. had the maximum cover recorded in the roadcuts (ca. 10\%), although this species was present in only one plot at this scenario type (Table 1). Enchylium complex was the only species found in the embankments; present in five out of our plots (Table 1) and with a maximum recorded cover of $2 \%$. (a) Biocrust richness

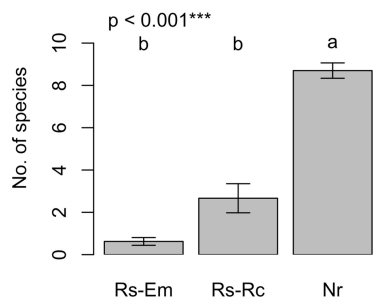

(b) Biocrust cover

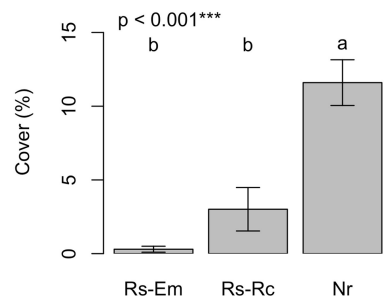

Figure 2. Average values ( $\pm \mathrm{SE}$ ) for biocrust richness and cover. Rs-Em: embankments; Rs-Rc: roadcuts; Nr: natural remnants. For each graph the significance value of the Kruskal-Wallis test is given. Different letters indicate significant differences (ConoverIman test for post hoc comparisons, $p<0.05$ ) among environmental scenarios.

Species richness showed a tendency to increase in the following order: embankments $<$ roadcuts $<$ natural remnants. However, this variable was statistically similar in the embankments and roadcuts (mean species richness of 0.6 and 2.7, respectively), while it increased significantly (up to 8.8) in the natural remnants (Fig. 2a). Similarly, total biocrust cover was significantly lower in the embankments and roadcuts (ca. $1 \%$ and $5 \%$, respectively) compared to the natural remnants (ca. $12 \%$, Fig. 2b).

The CWM for eutrophication and gypsum tolerance was similar in roadcuts and natural remnants $(p>0.050$, Fig. 3a, b), while CWM for thallus continuity was significantly lower in the roadcuts compared to the natural remnants (Fig. 3c). 
(a) Eutroph. tolerance

$p=0.051$

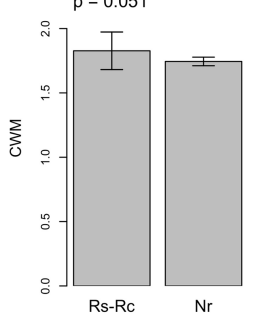

(b) Gypsum tolerance

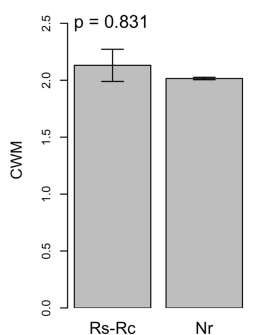

(c) Thallus continuity $p=0.036$

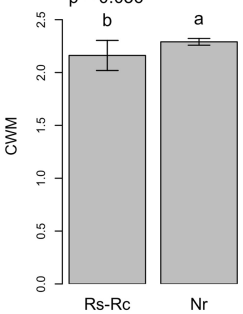

Figure 3. CWMs ( \pm SE) for eutrophication tolerance ("eutroph. tolerance"), gypsum tolerance and thallus continuity. Rs-Rc: roadcut; Nr: natural remnants. The significance value of the KruskalWallis test is given for each graph. Different letters indicate significant differences (Conover-Iman test for post hoc comparisons, $p<0.05)$ among environmental scenarios.

The RDA of biocrust composition using the type of scenario as the constraining variable showed a clear separation of roadcuts towards the positive end of the RDA1 axis from natural remnants. Also, biocrust composition was significantly correlated to $\mathrm{OC}, \mathrm{EC}, \mathrm{K}$, slope, acid phosphatase, stoniness and heat load (Fig. 4a). The characteristic species with centroids at this positive extreme were Enchylium complex, Gyalolechia complex, Leproloma sp. and Placidium complex (results not shown). The type of scenario (roadcuts vs. natural remnants) significantly explained ( $F=3.51$, $p=0.001$ ) $6.1 \%$ of variance of the RDA (Fig. 4a). However, after removing the variation given by topography and soil variables, the partial RDAs (Fig. $4 \mathrm{~b}$ and c) were not significant $(F=0.96, p=0.440$ and $F=0.75, p=0.630$, respectively). In contrast, the partial RDA after removing the variation given by plant cover (Fig. 4d) remained significant $(F=3.68, p=0.002)$

\section{Discussion}

Previous work on unassisted revegetation of newly created habitats has mostly focused on vascular plants, while the recovery of biocrust communities has been disregarded. Moreover, to our knowledge, this is the first study assessing natural recovery of biocrusts (i.e., unassisted) in road slopes. Our results showed that biocrusts can colonize and establish on road slopes, particularly after soil excavation (i.e., as in roadcuts). Surprisingly, biocrust communities developed on roadcuts were relatively similar in composition to those on some natural remnants. Moreover, we found that topography and fine-scale soil properties were more important than the type of environmental scenario (i.e., roadcuts vs. natural remnants) in determining biocrust species composition. Nevertheless, our results suggest that the scenario type may exert some influence on biocrust establishment and development mediated by the vascular plant community configuration associated with each scenario.

\subsection{Natural recovery of biocrusts on new habitats}

Although some biocrust components such as cyanobacteria, algae and even mosses are regarded as early colonizers in primary succession (Belnap and Eldridge, 2003), little is known about their potential to colonize and establish in newly created habitats without human assistance. For example, biocrusts (including lichens and mosses) were found to be the dominant life form in the first $100 \mathrm{~m}$ after 10 years of glacier retreat in a Canadian deglaciated valley (Breen and Lévesque, 2008) and widespread communities after $\sim 20$ years of lava flows (Jackson, 1971). However, only a couple of studies have assessed biocrust colonization and establishment in human-made habitats. Gypser et al. $(2016,2015)$ evaluated the structural and functional development of biocrusts in post-mining sites in German drylands. These authors found that 13-23 years after mining activity cessation, biocrust communities were able to colonize the new substrate, mostly composed of applied tertiary and quaternary materials, initially as green algae-moss communities and developing into rich and extensive moss-lichen carpets over years (Gypser et al., 2016, 2015). Also, Gypser et al. (2015) reported an increase in biocrust NDVI (normalized difference vegetation index) and chlorophyll fluorescence with biocrust developmental state, evidencing the functional recovery of these communities in a relatively short time (i.e., $<20$ years). Similarly, our results showed that lichen-biocrusts can recover naturally as fast as 20 years after habitat creation, i.e., approximate date of road slope construction, but only in roadcuts. It is worth noting that although almost half of the species present in natural remnants were found in roadcuts, biocrust richness and cover were still notably lower than in natural remnants. Nevertheless, these results contrast with estimated recovery rates for biocrusts in a machine-cleared road scenario (Lalley and Viles, 2008), which ranged from the multi-decade to the multi-century scale. The great differences in recovery times are likely due to climate, semiarid vs. hyper-arid in the case of Lalley and Viles (2008), but also to the availability and proximity of biocrust inoculum. Actually, when topsoil surface is removed at fine scales, e.g., as in scalped patches of less than $1 \mathrm{~m}^{2}$ and immediately surrounded by biocrust material, biocrust recovery can be as fast as 3 years for cyanobacteria or lower than 5 years for bryophytes (Dojani et al., 2011; Tian et al., 2006). In our study, remnants of natural habitat with well-developed biocrusts are only a few metres apart from the road slopes, which may have favored and speeded up the colonization process at our study scale (i.e., sufficient biocrust inoculum availability). 
(a) RDA

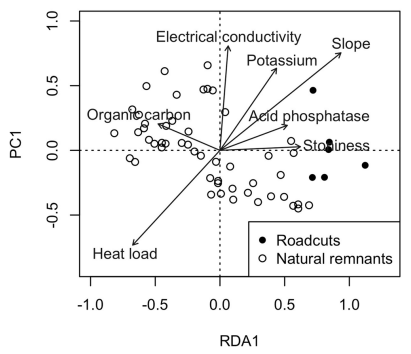

(c) Partial RDA soil

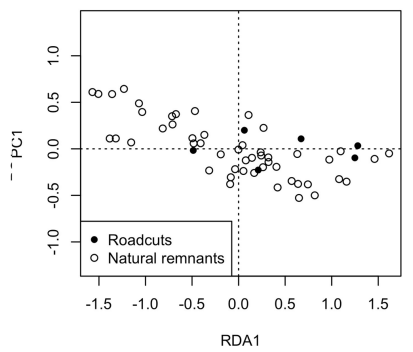

(b) Partial RDA topography

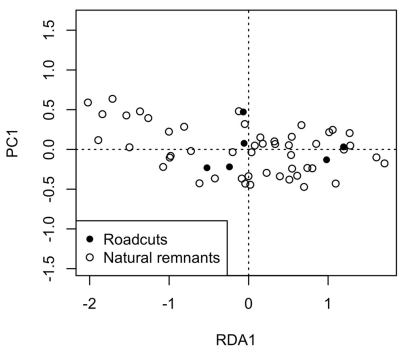

(d) Partial RDA plant cover

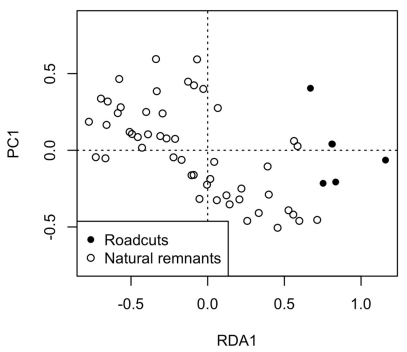

Figure 4. (a) RDA using the type of scenario as the constraining variable. (b, c, d) Partial RDAs using the type of scenario as the constraining variable, in which the variation attributable to (b) topography, (c) soil and (d) plant cover was removed before adjusting the model. RDA ordination plots are based on the first and only RDA axis (RDA1) and the following most explanatory PCA axis (PCA1). Variables that significantly adjust to the RDA $(p<0.05)$ are represented by arrows.

\subsection{Biocrust structure and composition across environmental scenarios are mostly driven by topography and edaphic factors}

Our results also showed that biocrust richness and cover were notably lower in road slopes than in adjacent natural areas and that the newly established communities were characterized by a lower thallus continuity CWM. Moreover, striking differences between roadcuts and embankments were found in terms of species number. Specifically, only one species, Enchylium complex, was found on embankments, while roadcuts and natural remnants had a total of 8 and 18 species, respectively. Firstly, these results are likely due to the typically marked structural dissimilarities between embankments and roadcuts (Arenas et al., 2017a; Jimenez et al., 2011), although the studied soil properties were generally similar in these scenario types. Roadcuts are constructed by excavation, generating areas of exposed bedrock and bare soil, while embankments are constructed by heaping and compacting material and generally applying topsoil treatments (Tormo et al., 2009). The artificially created topsoil in the embankments is likely to limit the number of biocrust species able to colonize and establish in these scenarios because, among the potential edaphic factors responsible for biocrust establishment, soil stability has been widely recognized as one of the most relevant. In particular, older soils, embedded and shallower (more stable) at roadcuts, are likely to promote a faster recovery of biocrusts (Belnap and Eldridge, 2003). Conversely, soil structure and age may also explain the presence of only one species, Enchylium complex, in the embankments where less stable, younger and deeper soils formed by applied materials may dominate. Nevertheless, Enchylium spp. have been identified as early successional biocrust species (Belnap and Eldridge, 2003) and play an important ecological role in the development of new habitats; the photobiont of these lichens is a cyanobacteria able to fix $N$, and thus contribute to the improvement of soil properties for the next successional stages.

Although we did not characterize soil texture, this soil property has been found to be different in roadcuts and embankments in other road slopes; i.e., roadcuts have coarser soils than embankments (Jimenez et al., 2011). Indeed, soil stoniness in roadcuts tended to be higher than in embankments in our study area. This may have benefited biocrust development because scattered rocks or rock fragments can act as microclimatic shelters (e.g., reducing solar radiation) and as nutrient and biocrust inoculum traps, among others (Bowker et al., 2016). Additionally, we found no significant differences in topography between embankments and roadcuts, but slope values tended to be higher in the roadcut scenario. Steeper slopes and coarser soils, typically found in roadcuts, may explain the generally lower plant cover in this scenario type due to the potential difficulty for seeds to establish and grow (Bochet and García-Fayos, 2004) or the lower water availability (Jimenez et al., 2011), among other factors. In turn, vascular plant cover can also be determinant in biocrust establishment and development.

On the one hand, it is generally accepted that biocrust communities are more abundant and diverse in open ecosystems with sparse plant cover (Bowker et al., 2016), where competition for space is lower. On the other hand, the more benign microclimate created by plants (e.g., lower solar radiation, higher humidity) in drylands can benefit biocrust physiological performance (Hui et al., 2013; Niemi et al., 2002; Singh et al., 2012), although shaded vs. open environment preference can be highly species-specific (ConcostrinaZubiri et al., 2014; Eldridge et al., 2002). Moreover, multiple relationships between biocrusts and soil properties mediated by plants are expected to play a critical role in biocrust community configuration, even though they have been poorly studied (Zhang et al., 2016). Here, vascular plant cover tended to be higher in the embankments (39\%) than in the roadcuts (29\%, Table 3). However, biocrust presence in the embankments was represented by only one species and it was exclusively recorded at those sites with plant cover $>30 \%$ (results not shown). It is also worth noting that although we only estimated the cover of perennial plants, we are aware that annual plants can occupy almost the totality of perennial plant interspaces in the studied embankments, but not in the roadcuts (personal observation). This suggests that in embankments - habitats with less favorable soil condi- 
tions for biocrusts, as mentioned above - perennial and annual plant communities out-compete biocrusts by limiting habitat space availability. This hypothesis is somehow supported by the fact that the roadcut with the lowest perennial plant cover registered a remarkably high cover of biocrusts (ca. 9\%, results not shown). Notwithstanding, our results suggest that complex biotic-abiotic interactions operate in our road slopes. Further work should explore the type (positive vs. negative) and magnitude of the effects that both perennial and annual plants, biocrusts and soil properties exert on each other at very fine scales to better understand the natural recovery process of these newly created habitats.

Secondly, we expected that biocrust communities at roadcuts and natural remnants would show differences in particular ecological features such as gypsum and eutrophication tolerance and thallus continuity. Surprisingly, communities at both types of scenarios were rather similar in terms of gypsum and eutrophication tolerance. However, these findings suggest that roadcuts and natural remnants present small differences in gypsum content and nutrient inputs, or conversely that biocrust species can adapt well to varying environmental conditions related to soil and air composition when sufficient microhabitat is available (i.e., low plant cover). Also, as we hypothesized, biocrust communities had a slightly lower CWM for thallus continuity in the roadcuts, where less rough surfaces can be found. Our results are in accordance with the generally accepted scheme for biocrust succession, where organisms with smaller structural units (e.g., cyanobacteria and algae) are the first to colonize new surfaces, while more continuous covers of lichens and mosses are found with time together with increased soil microrelief (Belnap and Eldridge, 2003; Williams et al., 2012).

Finally, our results indicate that a particular combination of topographic factors and soil properties was shared between roadcuts and at least some of the adjacent natural remnants, leading to a similar species composition. It is well known that soil properties such as texture, fertility and $\mathrm{pH}$ are strong determinants of biocrust distribution patterns at the intermediate and local scales (reviewed in Bowker et al., 2016). Also, the solar radiation load can shape biocrust communities through direct effects on biocrust organisms (e.g., ultraviolet radiation received) or indirectly by regulating soil moisture and vascular plant development (Bowker et al., 2016). Accordingly, we found that biocrust composition in roadcuts and natural remnants was, at least in part, driven by topography, i.e., slope and heat load, and several soil properties related to soil structure, fertility and functioning, i.e., stoniness, EC, soil K, OC and acid phosphatase. Indeed, differences in biocrust composition between roadcuts and natural remnants were mainly due to soil and topographic characteristics, but not to the type of environmental scenario per se. This is in agreement with Concostrina-Zubiri et al. (2018), who reported that soil properties and topography explained biocrust diversity better than habitat structure (e.g., connectivity) and disturbance history (i.e., changes in habitat area) in the studied landscape. Nevertheless, our results also suggest that intrinsic characteristics of roadcuts (e.g., soil excavation, generally higher slopes), embankments (e.g., soil compacting) and natural remnants may exert an indirect effect on biocrust composition mediated by the particular plant community structure and composition associated with each environmental scenario.

\subsection{New application of biocrusts as restoration tools in disturbed drylands: recovery of road slope structure and function}

The role of biocrusts as restoration tools in drylands has been gaining attention during the last 2 decades. Biocrusts are natural, common components of drylands, where high abiotic stress conditions (i.e., high solar radiation, low water and nutrient inputs) typically combined with disturbance pressure such as grazing (Belnap, 2003) make them one of the most important elements for ecosystem structure and function, in comparison to other systems dominated by vascular plants. Due to their resistance to harsh environmental conditions and low resource requirements, together with their relative ease of handling and interesting functional attributes (e.g., carbon and nitrogen fixation, soil stabilization, soil-water dynamic regulation), biocrusts are regarded as key organisms in dryland restoration research. In fact, higher biocrust cover has been related to increased soil stability on road slopes in Mediterranean grasslands, contributing to the improvement of soil condition even more than vascular plants (GarcíaPalacios et al., 2011). Therefore, restoration strategies in drylands should begin to consider biocrusts as relevant communities in the ecosystem recovery process, as opposed to the traditional "vascular-plants only" approach. Indeed, it would be interesting to test if the high vascular plant cover found in road slopes (ca. 30\%-40\% of mean cover; Arenas et al., 2017a) is due to the amelioration of the initial soil conditions by lichen and other biocrust types.

So far, it has been shown that biocrusts - including lichens - can be grown artificially in the greenhouse rapidly (Doherty et al., 2015; Bowker and Antoninka, 2016), and under field conditions as well (Xiao et al., 2015). Moreover, a few experiments have successfully applied biocrusts in the field, and continued growing and functioning have been recorded, at least at the short term (Chiquoine et al., 2016; Condon and Pyke, 2016; Antoninka et al., 2017). Soil properties such as organic matter content, the inoculum type (i.e., field-collected vs. greenhouse-cultured), the climatic similarity of collection and application zone and the initial species composition of biocrusts to be applied are key points for the success of biocrust re-establishment (Condon and Pike, 2016; Bowker and Antoninka, 2016; Bowker et al., 2017; Antoninka et al., 2017). Here, we show that initial soil characteristics, as given by road slope type, are critical to sustaining relatively rich and diverse biocrusts in a road construction context: biocrust restoration efforts should be focused on ex- 
cavated areas where bare soil and exposed bedrock dominate (e.g., roadcuts).

Recently, the application of biocrust cyanobacteria inoculum (i.e., assisted recovery) has been identified as an effective method for biocrust restoration in road slopes, speeding up the recovery rate of biocrust cover and function to periods shorter than 2 years (Chiquoine et al., 2016). For biocrust lichens, thalli translocation with the use of adhesives such as glue or simply water addition has also been proposed as an effective measure to improve biocrust establishment and assure functional recovery in disturbed gypsum soils (Ballesteros et al., 2017). In this context, common and/or relatively abundant species in road slopes such as Enchylium spp. or Gyalolechia spp. can be considered promising species for active biocrust restoration. Indeed, it would be interesting to collect specimens of these species at sites that will be converted to road slopes before the disturbance begins, store them and then transplant them after construction. Conversely, our findings suggest that natural colonization can also be regarded as an interesting restoration option; although ecosystem recovery may take longer to occur, it has the advantage of increasing local diversity in these human-made ecosystems as well as being highly costeffective (Prach and Hobbs, 2008).

\section{Conclusions}

Biocrust restoration offers an interesting opportunity to recover soil structure and function in disturbed drylands and provides an alternative to traditional restoration techniques using vascular vegetation (Bowker, 2007). This study evidences that lichen biocrusts can establish naturally on newly created habitats without any human assistance. We also show that topography and edaphic factors related to soil physical characteristics (structure of roadcuts vs. embankments, stoniness), composition and functioning (as indicated by $\mathrm{OC}, \mathrm{K}, \mathrm{EC}$ and acid phosphatase values) play an important role in the configuration of new biocrust communities on timescales of $<20$ years. Actually, we found that roadcuts and natural remnants with similar topography and soil properties shared similar biocrust species composition. Our findings thus suggest that given a certain combination of initial soil properties and topographic factors, biocrusts will likely develop successfully with no further actions needed. Conversely, our results provide a number of promising species for active biocrust restoration in Mediterranean road slopes, since they are common (e.g., Enchylium spp.) or can achieve relatively high cover (e.g., Gyalolechia spp.) in such environmental scenarios. Previous work has pointed out the role of biocrusts in promoting soil stability in road slopes of Mediterranean grasslands (García-Palacios et al., 2011). Future research should evaluate the effect of lichens and other biocrust groups (e.g., cyanobacteria) on the improvement of topsoil properties such as texture, nutrient content and micro- bial activity and assess biocrust-vascular plant interactions over time. This would allow us to better quantify the contribution of biocrusts to ecosystem development in new landscapes created after the construction of linear infrastructures. This is particularly relevant in drylands due to their vulnerability to land-use change (Reynolds et al., 2007).

Data availability. Data are available from the Zenodo digital repository: https://doi.org/10.5281/zenodo.3237017 (ConcostrinaZubiri et al., 2019).

Supplement. The supplement related to this article is available online at: https://doi.org/10.5194/we-19-39-2019-supplement.

Author contributions. LCZ, JMA, IM and AE conceived and designed the study, LCZ and JMA conducted field work, JMA and LCZ analyzed the data, and LCZ, JMA, IM and AE wrote the paper.

Competing interests. The authors declare that they have no conflict of interest.

Acknowledgements. L. Concostrina-Zubiri and J. M. Arenas were supported by the REMEDINAL-3 (S2013/MAE-2719) of the Comunidad de Madrid, Spain, and by the European Union (Gypworld H2020-MSCA-RISE-2017-777803). We thank the two anonymous reviewers for their comments, which improved an earlier version of the paper.

Financial support. This research has been supported by the R\&D Department of Obrascon Huarte Lain, S.A. (OHL), the Spanish Ministry of Economy and Competitiveness (grant nos. ECONECT CDTI IDI-20120317 and ROOTS-CGL2015-66809-P), and the Madrid regional government (grant nos. REMEDINAL-2 S-2009/AMB-1783 and REMEDINAL-3 S2013/MAE-2719).

Review statement. This paper was edited by Daniel Montesinos and reviewed by two anonymous referees.

\section{References}

Antoninka, A., Bowker, M. A., Chuckran, P., Barger, N. N., Reed, S., and Belnap, J.: Maximizing establishment and survivorship of field-collected and greenhouse-cultivated biocrusts in a semi-cold desert, Plant Soil, 429, 1-13, https://doi.org/10.1007/s11104-017-3300-3 2017.

Arenas, J. M., Escudero, A., Mola, I., and Casado, M. A.: Roadsides: an opportunity for biodiversity conservation, Appl. Veg. Sci., 20, 527-537, https://doi.org/10.1111/avsc.12328, 2017a. 
Arenas, J. M., Lázaro-Lobo, A., Mola, I., Escudero, A., and Casado, M. A.: The influence of site factors and proximity of adjacent vegetation on tree regeneration into roadslopes, Ecol. Eng., 101, 120-129, https://doi.org/10.1016/j.ecoleng.2017.01.007, 2017b.

Arup, U., Søchting, U., and Frödén, P.: A new taxonomy of the family Teloschistaceae, Nordic J. Bot., 31, 016-083, https://doi.org/10.1111/j.1756-1051.2013.00062.x, 2013.

Ballesteros, M., Ayerbe, J., Casares, M., Cañadas, E. M., and Lorite, J.: Successful lichen translocation on disturbed gypsum areas: A test with adhesives to promote the recovery of biological soil crusts, Sci. Rep., 7, 45606, https://doi.org/10.1038/srep45606, 2017.

Belnap, J.: The world at your feet: desert biological soil crusts, Front. Ecol. Environ., 1, 181-189, https://doi.org/10.1890/15409295(2003)001[0181:TWAYFD]2.0.CO;2, 2003.

Belnap, J. and Eldridge, D.: Disturbance and recovery of biological soil crusts, in: Biological soil crusts: structure, function, and management, edited by: Belnap, J. and Lange, O. L., Springer, Berlin, Germany, 364-383, 2003.

Bochet, E. and García-Fayos, P.: Factors controlling vegetation establishment and water erosion on motorway slopes in Valencia, Spain. Rest. Ecol., 12, 166-174, https://doi.org/10.1111/j.10612971.2004.0325.x, 2004.

Bochet, E., García-Fayos, P., Alborch, B., and Tormo, J.: Soil water availability effects on seed germination account for species segregation in semiarid roadslopes, Plant Soil, 295, 179-191, https://doi.org/10.1007/s11104-007-9274-9, 2007.

Bowker, M. A.: Biological soil crust rehabilitation in theory and practice: an underexploited opportunity, Restor. Ecol., 15, 1323, https://doi.org/10.1111/j.1526-100X.2006.00185.x, 2007.

Bowker, M. A. and Antoninka, A. J.: Rapid ex situ culture of Nfixing soil lichens and biocrusts is enhanced by complementarity, Plant. Soil, 408, 415-428, https://doi.org/10.1007/s11104-0162929-7, 2016.

Bowker, M. A., Belnap, J., Davidson, D. W., and Goldstein, H.: Correlates of biological soil crust abundance across a continuum of spatial scales: support for a hierarchical conceptual model, J. App. Ecol., 43, 152-163, https://doi.org/10.1111/j.13652664.2006.01122.x, 2006.

Bowker, M. A., Belnap, J., Büdel, B., Sannier, C., Pietrasiak, N., Eldridge, D. J., and Rivera-Aguilar, V.: Controls on distribution patterns of biological soil crusts at micro-to global scales, in: Biological soil crusts: an organizing principle in drylands, edited by: Weber, B., Büdel, B., and Belnap, J., Springer, Cham, Switzerland, 173-197, https://doi.org/10.1007/978-3-319-30214-0_16, 2016.

Bowker, M. A., Antoninka, A. J., and Durham, R. A.: Applying community ecological theory to maximize productivity of cultivated biocrusts, Ecol. Appl., 27, 1958-1969, https://doi.org/10.1002/eap.1582, 2017.

Breen, K. and Lévesque, E.: The influence of biological soil crusts on soil characteristics along a High Arctic glacier foreland, Nunavut, Canada, Arct. Antarct. Alp. Res., 40, 287-297, https://doi.org/10.1657/1523-0430(06-098)[BREEN]2.0.CO;2, 2008.

Chamizo, S., Cantón, Y., Lázaro, R., and Domingo, F.: The role of biological soil crusts in soil moisture dynamics in two semiarid ecosystems with contrasting soil textures, J. Hydrol., 489, 74-84, https://doi.org/10.1002/hyp.11493, 2013.
Chiquoine, L. P., Abella, S. R., and Bowker, M. A.: Rapidly restoring biological soil crusts and ecosystem functions in a severely disturbed desert ecosystem, Ecol. Appl., 26, 1260-1272, 2016.

Concostrina-Zubiri, L., Martínez, I., Rabasa, S. G., and Escudero, A.: The influence of environmental factors on biological soil crust: from a community perspective to a species level approach, J. Veg. Sci., 25, 503-513, https://doi.org/10.1111/jvs.12084, 2014.

Concostrina-Zubiri, L., Martínez, I., and Escudero, A.; Lichenbiocrust diversity in a fragmented dryland: Fine scale factors are better predictors than landscape structure, STOTEN, 628, 882892, https://doi.org/10.1016/j.scitotenv.2018.02.090, 2018.

Concostrina-Zubiri, L., Arenas, J. M., Martínez, I., and Escudero, A.: Biocrusts on dryland road slopes, Zenodo Digital Repository, https://doi.org/10.5281/zenodo.3237017, 2019

Condon, L. A. and Pyke, D. A.: Filling the interspace-restoring arid land mosses: source populations, organic matter, and overwintering govern success, Ecol. Evol., 6, 7623-7632, https://doi.org/10.1002/ece3.2448, 2016.

Delgado-Baquerizo, M., Gallardo, A., Covelo, F., Prado-Comesaña, A., Ochoa, V., and Maestre, F. T.: Differences in thallus chemistry are related to species-specific effects of biocrust-forming lichens on soil nutrients and microbial communities, Func. Ecol., 29, 1087-1098, https://doi.org/10.1111/1365-2435.12403, 2015.

de Mendiburu, F.: Package "agricolae", R Package Version 1.2-8, 2017.

Doherty, K. D., Antoninka, A. J., Bowker, M. A., Ayuso, S. V., and Johnson, N. C.: A novel approach to cultivate biocrusts for restoration and experimentation, Ecol. Restor., 33, 13-16, https://doi.org/10.3368/er.33.1.13, 2015.

Dojani, S., Büdel, B., Deutschewitz, K., and Weber, B.: Rapid succession of biological soil crusts after experimental disturbance in the Succulent Karoo, South Africa, Appl. Soil Ecol., 48, 263 269, https://doi.org/10.1016/j.apsoil.2011.04.013, 2011.

Elbert, W., Weber, B., Burrows, S., Steinkamp, J., Büdel, B., Andreae, M. O., and Pöschl, U.: Contribution of cryptogamic covers to the global cycles of carbon and nitrogen, Nat. Geosci., 5, 459, https://doi.org/10.1038/ngeo1486, 2012.

Eldridge, D. J., Zaady, E., and Shachak, M.: Microphytic crusts, shrub patches and water harvesting in the Negev Desert: the Shikim system, Landsc. Ecol., 17, 587-597, https://doi.org/10.1023/a:1021575503284, 2002.

Fischer, T. and Subbotina, M.: Climatic and soil texture threshold values for cryptogamic cover development: a meta analysis, Biol., 69, 1520-1530, https://doi.org/10.2478/s11756-014-04647, 2014.

García-Palacios, P., Bowker, M. A., Maestre, F. T., Soliveres, S., Valladares, F., Papadopoulos, J., and Escudero, A.: Ecosystem development in roadside grasslands: biotic control, plant-soil interactions, and dispersal limitations, Ecol. Appl., 21, 2806-2821, https://doi.org/10.1890/11-0204.1, 2011.

Gypser, S., Veste, M., Fischer, T., and Lange, P.: Formation of soil lichen crusts at reclaimed post-mining sites, Lower Lusatia, North-east Germany, Graphis Scripta, 27, 3-14, 2015.

Gypser, S., Herppich, W. B., Fischer, T., Lange, P., and Veste, M.: Photosynthetic characteristics and their spatial variance on biological soil crusts covering initial soils of post-mining sites in Lower Lusatia, NE Germany, Flora- 
Morphology, Distribution, Funct. Ecol. Plant., 220, 103-116, https://doi.org/10.1016/j.flora.2016.02.012, 2016.

Hladun, N. and Llimona, X.: Checklist of the lichens and lichenicolous fungi of the Iberian Peninsula and Balearic Islands, available at: http://botanica.bio.ub.es/checklist/checklist.htm (last access: 1 December 2011), 2002-2007.

Hui, R., Li, X. R., Chen, C. Y., Zhao, X., Jia, R., Liu, L., and Wei, Y.: Responses of photosynthetic properties and chloroplast ultrastructure of Bryum argenteum from a desert biological soil crust to elevated ultraviolet-B radiation, Physiol. Plant., 147, 489-501, https://doi.org/10.1111/j.1399-3054.2012.01679.x, 2013.

Jackson, T. A.: Study of the Ecology of Pioneer Lichens, Mosses, and Algae on Recent Hawaiian Lava Flows, Pac. Sci., 25, 22-32, https://doi.org/10125/6105, 1971.

Jimenez, M. D., Ruiz-Capillas, P., Mola, I., Pérez-Corona, E., Casado, M. A., and Balaguer, L.: Soil development at the roadside: a case study of a novel ecosystem, Land. Degrad. Dev., 24, 564-574, https://doi.org/10.1002/ldr.1157, 2011.

Jimenez Aguilar, A., Huber-Sannwald, E., Belnap, J., Smart, D. R., and Moreno, J. A.: Biological soil crusts exhibit a dynamic response to seasonal rain and release from grazing with implications for soil stability, J. Arid. Environ., 73, 1158-1169, https://doi.org/10.1016/j.jaridenv.2009.05.009, 2009.

Lalley, J. S. and Viles, H. A.: Recovery of lichen-dominated soil crusts in a hyper-arid desert, Biodivers. Conserv., 17, 1-20, https://doi.org/10.1007/s10531-007-9153-y, 2008.

Legendre, P. and Gallagher, E. D.: Ecologically meaningful transformations for ordination of species data, Oecologia, 129, 271280, https://doi.org/10.1007/s004420100716, 2001.

Luzuriaga, A. L., Sánchez, A. M., Maestre, F. T., and Escudero, A.: Assemblage of a semi-arid annual plant community: abiotic and biotic filters act hierarchically, PloS one, 7, e41270, https://doi.org/10.1371/journal.pone.0041270, 2012.

McCune, B. and Grace, J. B.: Analysis of Ecological Communities, MJM Software Design, Gleneden Beach, Oregon, USA, 2002.

McCune, B. and Keon, D.: Equations for potential annual direct incident radiation and heat load, J. Veg. Sci., 13, 603-606, https://doi.org/10.1111/j.1654-1103.2002.tb02087.x, 2002.

Mola, I., Jiménez, M. D., López-Jiménez, N., Casado, M. A., and Balaguer, L.: Roadside reclamation outside the revegetation season: management options under schedule pressure, Restor. Ecol., 19, 83-92, https://doi.org/10.1111/j.1526-100X.2009.00547.x, 2011.

Niemi, R., Martikainen, P. J., Silvola, J., Sonninen, E., Wulff, A., and Holopainen, T.: Responses of two Sphagnum moss species and Eriophorum vaginatum to enhanced UV-B in a summer of low UV intensity, New Phytol., 156, 509-515, https://doi.org/10.1046/j.1469-8137.2002.00532.x, 2002.

Nimis, P. L. and Martellos, S.: ITALIC - The Information System on Italian Lichens, Version 5.0, University of Trieste, Dept. of Biology, available at: http://dryades.units.it/italic (last access: 7 January 2019, 2016.

Ninyerola, M., Pons, X., and Roure, J.: Atlas Climático Digital de la Península Ibérica Metodología y aplicaciones en bioclimatología y geobotánica, Universidad Autónoma de Barcelona, Bellaterra, Spain, 2005.

Ochoa-Hueso, R., Hernandez, R. R., Pueyo, J. J., and Manrique, E.: Spatial distribution and physiology of biological soil crusts from semi-arid central Spain are related to soil chem- istry and shrub cover, Soil Biol. Biochem., 43, 1894-1901, https://doi.org/10.1016/j.soilbio.2011.05.010, 2011.

Oksanen, J., Blanchet, F. G., Friendly, M., Kindt, R., Legendre, P., McGlinn, D., Minchin, P. R., O’Hara, R. B., Simpson, G. L., Solymos, P., Henry, M., Stevens, H., Szoecs, E., and Wagner, H.: vegan: Community ecology package, $\mathrm{R}$ package version $2.5-2$, 2018.

Otálora, M. A., Jørgensen, P. M., and Wedin, M.: A revised generic classification of the jelly lichens, Collemataceae, Fungal Divers., 64, 275-293, https://doi.org/10.1007/s13225-013-0266-1, 2014.

Pintado, A., Sancho, L. G., Green, T. G. A., Blanquer, J. M., and Lázaro, R.: Functional ecology of the biological soil crust in semiarid SE Spain: sun and shade populations of Diploschistes diacapsis (Ach.) Lumbsch., Lichenologist, 37, 425-432, https://doi.org/10.1017/S0024282905015021, 2005

Prach, K. and Hobbs, R. J.: Spontaneous succession versus technical reclamation in the restoration of disturbed sites, Restor. Ecol., 16, 363-366, https://doi.org/10.1111/j.1526100X.2008.00412.x, 2008.

Prieto, M., Aragón, G., and Martínez, I.: The genus Catapyrenium s. lat. (Verrucariaceae) in the Iberian Peninsula and the Balearic Islands, Lichenologist, 42, 637-684, https://doi.org/10.1017/S0024282910000319, 2010a.

Prieto, M., Martínez, I., and Aragón, G.: The genus Placidiopsis in the Iberian Peninsula and the Balearic Islands, Mycotaxon, 114, 463-472, https://doi.org/10.5248/114.463, 2010 b.

Prieto, M., Martínez, I., Aragón, G., Gueidan, C., and Lutzoni, F.: Molecular phylogeny of Heteroplacidium, Placidium, and related catapyrenioid genera (Verrucariaceae, lichen-forming Ascomycota), Am. J. Bot., 99, 23-35, https://doi.org/10.3732/ajb.1100239, 2012.

Reynolds, J. F., Smith, D. M. S., Lambin, E. F., Turner II, B. L., Mortimore, M., Batterbury, S. P., Downing, T. E., Dowlatabadi, H., Fernandez, R. J., Herrick, J. E., HuberSannwald, E., Jiang, H., Leemans, R., Lynam, T., Maestre, F T., Ayarza, M., and Walker, B.,: Global desertification: building a science for dryland development, Science, 316, 847-851, https://doi.org/10.1126/science.1131634, 2007.

Singh, J., Gautam, S., and Pant, A. B.: Effect of UV-B radiation on UV absorbing compounds and pigments of moss and lichen of Schirmacher Oasis region, East Antarctica, Cell. Mol. Biol., 58, 80-84, https://doi.org/10.1170/T924, 2012.

Tian, G., Bai, X., Xu, J., and Wang, X.: Experimental studies on the natural restoration and the artificial culture of the moss crusts on fixed dunes in the Tengger Desert, China, Front. Biol. China, 1, 13-17, https://doi.org/10.1007/s11515-005-0006-3, 2006.

Tormo, J., Brochet, E., and García-Fayos, P.: Restauración y revegetación de taludes de carreteras en ambientes mediterráneos semiáridos: procesos edáficos determinantes para el éxito, Ecosistemas, 18, 79-90, 2009.

Weber, B., Büdel, B., and Belnap, J. (Eds.): Biological Soil Crusts: An Organizing Principle in Drylands, Springer, Cham, Switzerland, 2016a.

Weber, B., Bowker, M., Zhang, Y., and Belnap, J.: Natural Recovery of Biological Soil Crusts After Disturbance, in: Biological Soil Crusts: An Organizing Principle in Drylands, edited by: Weber, B., Büdel, B., and Belnap, J., Springer, Cham, Switzerland, 479498, https://doi.org/10.1007/978-3-319-30214-0, 2016 b. 
Williams, A. J., Buck, B. J., and Beyene, M. A.: Biological soil crusts in the Mojave Desert, USA: micromorphology and pedogenesis, Soil Sci. Soc. Am. J., 76, 1685-1695, https://doi.org/10.2136/sssaj2012.0021, 2012.

Xiao, B., Zhao, Y., Wang, Q., and Li, C.: Development of artificial moss-dominated biological soil crusts and their effects on runoff and soil water content in a semi-arid environment, J. Arid Environ., 117, 75-83, https://doi.org/10.1016/j.jaridenv.2015.02.017, 2015.
Zhang, Y., Aradottir, A. L., Serpe, M., and Boeken, B.: Interactions of biological soil crusts with vascular plants, in: Biological Soil Crusts: An Organizing Principle in Drylands, edited by: Weber B., Büdel B., and Belnap J., Springer, Cham, Switzerland, https://doi.org/10.1007/978-3-319-30214-0_19, 2016.

Zuur, A. F., Ieno, E. N., and Smith, G. M. (Eds.): Principal component analysis and redundancy analysis, in: Analysing Ecological Data, Springer New York, New York, USA, 193-224, https://doi.org/10.1007/978-0-387-45972-1_12, 2007. 